\title{
Thalassemia Distribution Based on Screening Programs in the Population of the East Malaysian State of Sabah
}

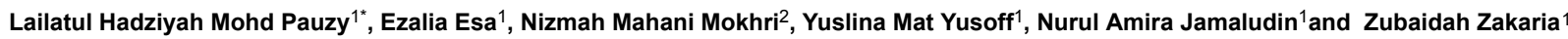

${ }^{1}$ Haematology Unit, Cancer Research Centre, Institute for Medical Research, Jalan Pahang, Kuala Lumpur, Malaysia

${ }^{2}$ Hospital Queen Elizabeth, Jalan Penampang, Penampang, Kota Kinabalu, Sabah, Malaysia

"Corresponding author: Lailatul H. M. Pauzy, Haematology Unit, Cancer Research Centre, Institute for Medical Research, Jalan Pahang, Kuala Lumpur, Malaysia, Tel: +603-2616 2666, E-mail: lailatul@imr.gov.my

Received date: October 20, 2017; Accepted date: January 07, 2018; Published date: January 31, 2018

Copyright: ( 2018 Pauzy LHM, et al. This is an open-access article distributed under the terms of the Creative Commons Attribution License, which permits unrestricted use, distribution, and reproduction in any medium, provided the original author and source are credited.

\begin{abstract}
Objective: The aim of the study is to examine the distribution of thalassemia in the indigenous population of Sabah where thalassemia is most prevalent in Malaysia based on screening programs carried out at the public health centers.

Method: A total of 645 blood samples were obtained from all over Sabah for thalassemia screening in the month of May 2013. High performance Liquid Chromatography and Capillary Electrophoresis were used for analyzing the hemoglobin subtypes.

Result: $94 \%$ of the total sample came from voluntary screening offered at primary care level and various government-promoted programs while the other $6 \%$ were cascade screening. The study included patients from the age of 1 to 73 years old. The majority $(97 \%$; 624/645) were indigenous people and $94 \%$ of the total sample came from voluntary screening offered at primary care level via various government promoted programs. $82 \%$ were female, mostly screened during their antenatal visit. 30\% (193/645) of the sample were tested positive for; $\beta$ Thalassemia trait $(78 \%$; 151/193), $\mathrm{HbE}$ trait $(10 \% ; 20 / 193)$, Homozygous $\mathrm{HbE}(2 \% ; 4 / 193)$ and other haemoglobinopathies $(7 \% ; 13 / 193)$. The other $3 \%(5 / 193)$ of the abnormal results were inconclusive hence would require further molecular analysis. Among all the indigenous people screened, the Kadazandusuns had the highest occurrence of haemoglobinopathies $(35 \% ; 87 / 250)$, followed by the Muruts $(33 \% ; 15 / 45)$, Malays $(29 \% ; 19 / 65)$, other races $(26 \% ; 46 / 180)$ and the Bajau people $(23 \% ; 19 / 84)$.
\end{abstract}

Conclusion: Thalassemia is prevalent in the indigenous population of Sabah and most people are asymptomatic. Government health clinics play a crucial role in promoting greater awareness of the disease via campaigns and screening programs as they are easily accessible and oftentimes are the first point of contact with the community.

Keywords: Heamoglobinopathies screening; Thalessemia diseases; $\beta$ Thalassaemia trait; Primary care; Antenatal; Sabah indigenous; Epidemiology

\section{Introduction}

Thalassemia is a heterogeneous group of disorders affecting hemoglobin synthesis which results in reduced production of $\alpha$ or $\beta$ globin chains of hemoglobin [1]. This autosomal-recessively inherited disease affects $7 \%$ of the world population [2] and is one of the commonest genetic conditions in South East Asia [3].

In Malaysia, thalassemia is a major public health issue with a large cost burden to the health ministry as treatment involved repeated blood transfusions, and long term monitoring for treatment side effect [4]. According to the Malaysian thalassemia registry, there are about 4541 registered thalassemia patients in Malaysia as of August 2009. Sabahans had the most number of registered patients standing at 1,272 with the Kadazandusun ethnic group contributing almost half of this number [5].

Sabah is an East Malaysia state located in the Borneo. Its population is estimated to be at 3.2 million people made up by 33 ethnic groups
[6]. The latest national census divided the main indigenous ethnic groups in Sabah into Kadazandusuns, Bajau, Malays, Muruts and other races [6].

Several studies had been done on molecular characterization of thalassemia genotypes in specific regions or ethnicities in Sabah in view of the high number of the cases there. From these studies, it is understood that each ethnic group possess its own unique set of mutations that lead to thalassemia $[7,8]$.

Studies done in the past decade have demonstrated that the mutations responsible for $\beta$-thalassemia disorders in the Sabah indigenous is the Filipino $\beta$-thalassemia deletion [9] whereas $\alpha$ thalassemia is commonly caused by a single $\alpha$-globin gene deletion [10]. Conversely, published data on the epidemiology of the disease in Sabah is still lacking.

Although the Malaysian thalassemia registry was funded in the year 2004 , access to the database is limited and reports on the epidemiology of different haemoglobinopathies in this highly prevalent state is still lacking. Thus, it is the aim of the study to examine and describe the distribution of thalassemia traits in the indigenous populations of 
Citation: Pauzy LHM, Esa E, Mokhri NM, Yusoff YM, Jamaludin NA, et al. (2018) Thalassemia Distribution Based on Screening Programs in the

Sabah through the voluntary screening programs initiated by the Ministry of Health, Malaysia.

\section{Materials and Methods}

Peripheral blood samples were obtained from health clinics and hospitals all over Sabah. All races were subjected to the same screening programs.

The samples are made up of patients who presented for voluntary screening, and cascade screening cases based on index cases. At least $2.5 \mathrm{ml}$ of peripheral blood was collected into EDTA tubes and full blood count (FBC) test was performed.

All samples with $\mathrm{MCH}$ values of $<27 \mathrm{pg}$ were further tested for thalassemia. This is in accordance with the Malaysia Clinical Practice Guidelines for Thalassemia Screening. Peripheral blood films were examined followed by the hemoglobin analysis.

The hemoglobin analysis was performed using High performance Liquid Chromatography (HPLC) using Bio- Rad Variant II HPLC and or Capillary Electrophoresis (CE) methods using Capillaries 2 Sebia, two of the recognized method for testing for $\mathrm{Hb}$ analysis [11].

Microscopic examination and $\mathrm{FBC}$ results were co-interpreted together with the Hemoglobin ( $\mathrm{Hb})$ Analysis results by the hematopathologists at the Institute for Medical Research (IMR), Kuala Lumpur, Malaysia. Results were then tabled in Microsoft Excel and descriptive analyses were conducted IBM SPSS software.

\section{Results}

In total, 645 samples were analyzed. Samples were received from 113 unique health Centers (Figure 1) with the majority (83\%) from primary care setting. The study included all patients from the age of 1year-old and the maximum age received was 73 years old with a mean age of 22.5 and median age of 23 years old. The indigenous people make up $97 \%$ of the total sample.

A larger proportion of the sample population is female (81\%), whom mostly took up the thalassemia screening when attending antenatal clinic. Up to $28 \%$ of the female sample and $41 \%$ of the male sample were tested positive for abnormal hemoglobin subtypes.

Most of the sample (94\%) came from voluntary screening program offered at primary care under various government promoted programs such as; adolescent screening programs and premarital screening program and the other $6 \%$ of the samples were cascade screening done for known family member affected by thalassemia. (See Table 1 for reasons for testing).

On average, $68 \%$ of the total sample under the voluntary screening program had no haemoglobinopathy as compared to only $50 \%$ of normal cases in the cascade 4 screening group.

Overall, thalassemia diseases affected $30 \%$ of the indigenous study population with the Kadazandusuns having the highest occurrence of diseases (35\%), followed by Murut (33\%), Malays (32\%), other indigenous (26\%) and Bajau (22\%) (See Tables 2, 3 and Figure 2 for breakdown of cases.).

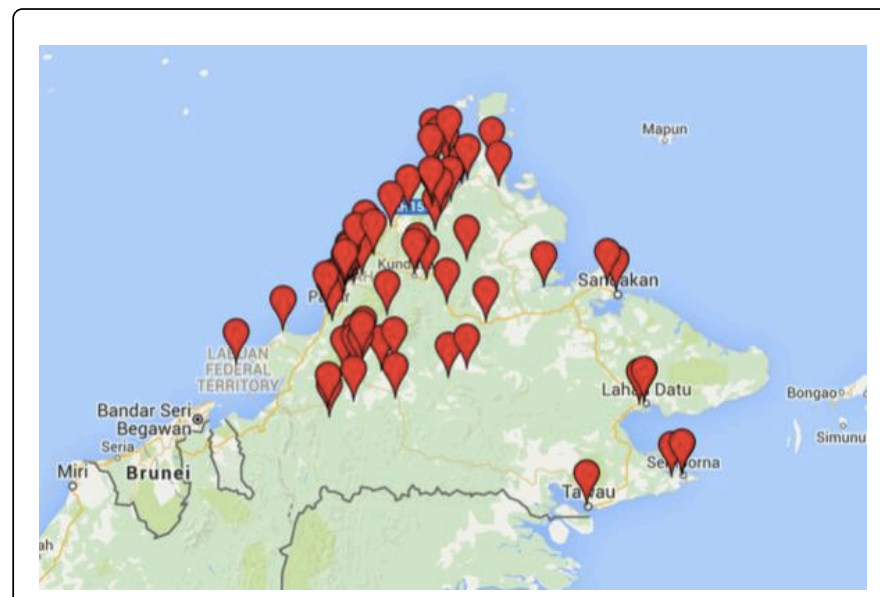

Figure 1: A map of the state of Sabah with individual primary health clinic where sample came from has been pin-marked. This map shows that sample came from all regions of Sabah, urban as well as rural areas.

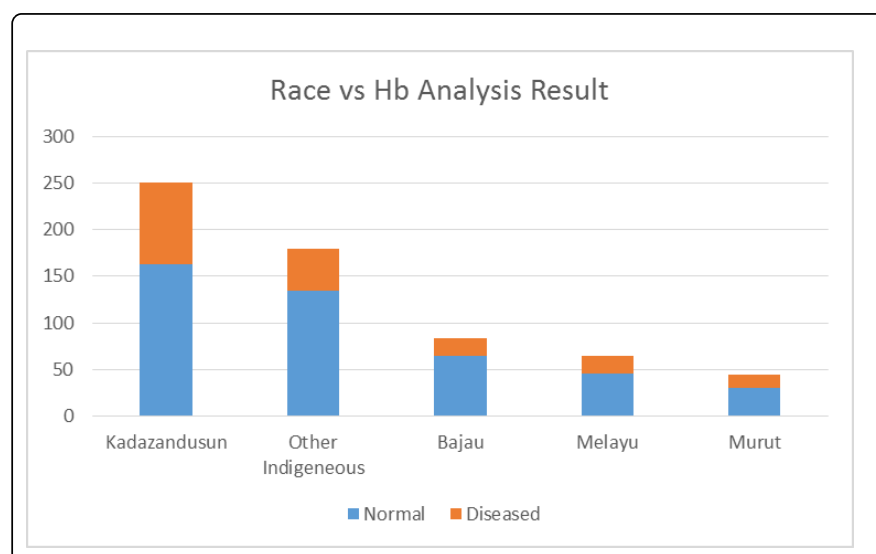

Figure 2: Diseased number of patients for each race. The Kadazandusuns have the highest percentage of occurances at $35 \%$ (87/250). ALso note that most sample received were from Kadazandusuns as this race constitutes the largest population in Sabah.

\begin{tabular}{|l|l|l|}
\hline & Frequency $(\mathbf{n})$ & Percent (\%) \\
\hline Screening offered at routine health follow-up & 278 & 43.1 \\
\hline Antenatal screening & 187 & 29 \\
\hline Adolescent screening programs & 106 & 16.4 \\
\hline Index/Cascade screening cases & 37 & 5.7 \\
\hline Premarital screening & 30 & 4.7 \\
\hline Others & 7 & 1.1 \\
\hline Total & 645 & 100 \\
\hline
\end{tabular}

Table 1: Screening programs from which the sample was acquitted. Majority taken during routine follow-up when the clinician noted abnormal FBC results. Antenatal screening and Adolescent screening 
Citation: Pauzy LHM, Esa E, Mokhri NM, Yusoff YM, Jamaludin NA, et al. (2018) Thalassemia Distribution Based on Screening Programs in the

Page 3 of 4

programs also contributed to a large percentage of samples as part of targeted screening.

\begin{tabular}{|c|c|c|c|c|c|}
\hline & & & \multicolumn{2}{|l|}{ Outcome } & \multirow{3}{*}{$\begin{array}{l}\text { Total } \\
250\end{array}$} \\
\hline & & & $\begin{array}{l}\text { Non- } \\
\text { diseased }\end{array}$ & $\begin{array}{l}\text { Disease } \\
\text { d }\end{array}$ & \\
\hline \multirow{10}{*}{ Race } & \multirow{2}{*}{$\begin{array}{l}\text { Kadazan } \\
\text { Dusun }\end{array}$} & Count & 163 & 87 & \\
\hline & & $\%$ within Race & $65.20 \%$ & $34.80 \%$ & $100.00 \%$ \\
\hline & \multirow[b]{2}{*}{ Bajau } & Count & 64 & 18 & 82 \\
\hline & & \% within Race & $78.00 \%$ & $22.00 \%$ & $100.00 \%$ \\
\hline & \multirow[b]{2}{*}{ Murut } & Count & 30 & 15 & 45 \\
\hline & & $\%$ within Race & $66.70 \%$ & $33.30 \%$ & $100.00 \%$ \\
\hline & \multirow[b]{2}{*}{ Malays } & Count & 25 & 12 & 37 \\
\hline & & $\%$ within Race & $67.60 \%$ & $32.40 \%$ & $100.00 \%$ \\
\hline & \multirow[b]{2}{*}{ Others } & Count & 170 & 61 & 231 \\
\hline & & $\%$ within Race & $73.60 \%$ & $26.40 \%$ & $100.00 \%$ \\
\hline \multirow{2}{*}{ Total } & & Count & 452 & 193 & 645 \\
\hline & & $\%$ within Race & $70.10 \%$ & $29.90 \%$ & $100.00 \%$ \\
\hline
\end{tabular}

Table 2: Breakdown of normal and diseased $\mathrm{Hb}$ analysis results among all the different races. The Kadazandusuns have the highest percentage of occurrence, followed by the Muruts, the Malays, other indigenous and the Bajau people.

\begin{tabular}{|l|l|l|}
\hline & Frequency (n) & Hb Analysis Result (\%) \\
\hline DNRO & 431 & 66.8 \\
\hline B TpaIT & 151 & 23.4 \\
\hline Normal & 21 & 3.3 \\
\hline E Trait & 20 & 3.1 \\
\hline Inconclusive & 5 & 0.8 \\
\hline Hb CS & 4 & 0.6 \\
\hline Homo E & 4 & 0.6 \\
\hline Total & 645 & 100 \\
\hline
\end{tabular}

DNRO: No abnormal subtypes detected however does not rule out alpha thalassaemia

$\beta$ Trait: Beta Thalassaemia trait

Normal: Normal $\mathrm{Hb}$ analysis

E Trait: HbE Trait

SEAO: South East Asian Ovalocytosis

Inconclusive: Further testing required

$\mathrm{Hb}$ CS: Hb Constant Springs

Home E: Homozygous $\mathrm{Hb} \mathrm{E}$

Table 3: Results of HB analysis of all the sample tested as performed by Acid / Alkaline Agarose gel electrophoresis, High Performance Liquid Chromatography and Capillary Electrophoresis. Among the abnormal $\mathrm{Hb}$ subtypes, beta-thalassemia constitutes the largest percentage.

\section{Discussion}

Latest data available from the Malaysian thalassemia registry shows that despite being only the third most populous state in Malaysia, Sabah has the largest number of registered thalassemia cases in Malaysia with the prevalence of 38.83 cases per 100,000 [12]. To our knowledge, we are the first to report on the epidemiology of thalassemia in this state and our key findings further detail the disease pattern in the state. This study demonstrated the high prevalence of thalassemia diseases in Sabah population, mainly $\beta$ thalassemia trait which affects $23 \%$ of the sample screened. This is higher than the estimated rate of $\beta$-thalassemia carrier in Malaysian population of $3-5 \%$ [12]. However, it must be noted that this study looks at the distribution in a targeted population sample thus must be interpreted with caution.

B-thalassemia major is one of the most severe types of thalassemia that pose a major public health problem in Malaysia $[13,14]$. Individuals with $\beta$ thalassemia trait are phenotypically asymptomatic. Children to both parents with $\beta$ thalassemia traits have $50 \%$ chance of becoming carriers themselves, and $25 \%$ chance of being $\beta$-thalassemia major [2,15]. Since interethnic marriage is also common in Sabah [10] this further strengthens the importance of screening of apparently asymptomatic individuals are especially in the Sabah population.

This study also confirms that the Kadazandusuns have the highest rate of thalassemia diseases among all the other indigenous population in Sabah, mirroring the finding from the Malaysian thalassemia registry [5]. Furthermore, a large number of the indigenous people still populate the more rural agricultural and fishing areas which may not have access to bigger, tertiary hospitals [10]. Another key finding of this study is that most screening sample comes from primary health clinics, which are more accessible for the rural populations making the screening program more widespread and effective. This is parallel with the plans for monitoring and surveillance system for thalassemia in Malaysia which propose for the health clinic to play the main role in the national screening program [16].

One of the main strategies in this screening program is target screening. Our study shows this is successfully promoted via adolescents screening programs done at schools. Screening this group of the population has been shown to be effective and despite the time gap between screening and marriage or pregnancy, the information was well conserved and resulted in testing of the partner [17]. Our study also reveals that most of the screening test sample comes from antenatal clinics. When a woman is detected to be a carrier of any haemoglobinopathy, her partner will be offered to be screened. This strategy is important to identify carriers of the disease in order to assess the risk of the couple having an affected child and subsequently to provide information on the options available to avoid such events in the future [18]. Delivery of screening test results should be complemented by genetic counseling and treatment options at every step of the way and this must be delivered tactfully taking into consideration the cultural, social and religious beliefs of the population $[15,18]$. However, at the present moment in Malaysia, the ruling of termination of pregnancy in the case of a fetus with a high-probability of being affected by thalassemia is not warranted.

\section{Conclusion}

In conclusion our study reported the high incidence of $\beta$ thalassemia trait in Sabah population. We also confirmed that among all the ethnics, the Kadazandusuns have the highest occurrence of 
Citation: Pauzy LHM, Esa E, Mokhri NM, Yusoff YM, Jamaludin NA, et al. (2018) Thalassemia Distribution Based on Screening Programs in the

Page 4 of 4

disease. We believe the delivery of screening programs in Sabah is comprehensive, via various program promotions and active role ensued by the primary health clinics. Continuous effort should be taken to sustain this program especially in Sabah, to lessen the burden of disease to the country. With optimization of the thalassemia screening and counseling programs, thalassemia would be a preventable disease in the future.

\section{Acknowledgement and Compliance with Ethical Standards}

The authors wish to thank the Malaysian Director General of Health for permission to publish this scientific paper. We would also like to thank the Deputy Director General (Research and Technical support, Ministry of Health) and the Institute for Medical Research (IMR) for their kind support. The authors would like to declare that there was no conflict of interest in this study. Our research was approved by the Institute for Medical Research Malaysia institutional review board and all procedures followed were in accordance with the ethical standards of the IRB.

\section{References}

1. Keohane EM (State university of N. J., Smith, L. J. (State U. of N. J. \& Walenga, J. M. (Loyola U. C. Rodak's Hematology Clinical Principles and Applications. (Elsevier, 2016).

2. Hoffbrand V, Moss PAH Essential Haematology. (Wiley, 2011).

3. Thong MK, Soo TL (2005) The spectrum of beta-globin gene mutations in children with beta-thalassaemia major from Kota Kinabalu, Sabah, Malaysia. Singapore Med J 46: 340-343.

4. Lan WS (2003) Management of thalasaemia. Health technology assesment unit, Medical Development Division Ministry of Health Malaysia 03, 137.

5. (2011) Malaysian Guideline for Good Clinical Practice. Malaysian Ministry of Health.
6. (2010) Population and Housing Cencus of Malaysia. Population Distribution and Basic Demographics Characteristics.

7. Orkin SH (1984) The mutation and human $\beta$-globin gene and its surrounding DNA.

8. Tan JAMA (2006) Characterisation and confirmation of rare betathalassaemia mutations in the Malay, Chinese and Indian ethnic groups in Malaysia. 38: 437-441.

9. Thong M (1999) A single, large deletion accounts for all the B-globin gene mutation in twenty families from Sabah (north Borneo), Malaysia. Hum Mutat 13: 413.

10. Tan JAMA (2010) High prevalence of alpha- and beta-thalassemia in the kadazandusuns in East Malaysia: Challenges in providing effective health care for an indigenous group. J Biomed Biotechnol 1-5.

11. Higgins T, Mack M, Khajuria (2009) A Comparison of two methods for the quantification and identification of hemoglobin variants. Clin Biochem 42: 701-705.

12. Ibrahim H (2009) Malaysia thalassaemia-current situation in control strategies and health system. Malaysian Thalessaemia Registry.

13. George E, Beta M (2001) Thalassemia major in Malaysia, an on - going public health problem. 56: 397-400.

14. Ezalia E (2014)Thalassaemia screening among healthy blood donors in hospital Tengku Ampuan Rahimah, Klang. 9: 44-52.

15. Petrou M (2013) In Prevention of thalassaemias and other haemoglobin disorders 1

16. (2016) Working group for Policy Development and Guidelines for National Thalassaemia Screening \& Prevention Program. National Thalassaemia Screening Program Malaysia.

17. Topal Y (2015)The Prevalence of Hemoglobinopathies in young adolescents in the province of Muğla in Turkey: results of a screening program. Hemoglobin 39: 247-250.

18. Cousens NE, Gaff CL, Metcalfe SA, Delatycki, MB (2010) Carrier screening for beta-thalassaemia: a review of international practice. Eur J Hum Genet 18: 1077-1083. 